\title{
PLANTAS COLORANTES UTILIZADAS POR LOS GUARANÍES DE MISIONES, ARGENTINA
}

\author{
HÉCTOR A. KELLER ${ }^{1}$
}

\begin{abstract}
Summary: Keller, H. A. 2010. Colorant plants used by Guaranis of Misiones, Argentina. Bonplandia 19(1): 11-25. ISSN: 0524-0476.

A study about natural resources used by Guaranis of Misiones Province as colorants is presented here. These resources are considered according to different aims of applications and classified in handicraft colorants, corporal dyes and tints for cloths. Several kinds of plants applications registered here at present are unusual. Techniques of acquire colorants and species employed are detailed, moreover some common designers used for body paint and baskets are described.
\end{abstract}

Key words: pigments, plant species, Ethnobotany, Mbya, Ava Chiripa.

Resumen: Keller, H. A. 2010. Plantas colorantes utilizadas por los Guaraníes de Misiones, Argentina. Bonplandia 19(1): 11-25. ISSN: 0524-0476.

Se presenta un estudio de los recursos vegetales colorantes utilizados por los guaraníes de Misiones, estos se abordan de acuerdo a los diferentes ámbitos de aplicación clasificándolos en colorantes para artesanías, pinturas corporales y tinturas para telas. Muchas de las aplicaciones que se registran aquí ya nos son usuales en la actualidad. Además de detallar las técnicas de obtención y las especies empleadas, se describen algunos de los diseños básicos empleados en pinturas corporales y cestería.

Palabras clave: pigmentos, especies vegetales, Etnobotánica, Mbya, Ava Chiripa.

\section{Introducción}

El hombre desde sus inicios utilizó tinturas vegetales para colorear diversas partes de su cuerpo, y tan pronto como se vistió, fue inevitable que tratara de aliviar la monotonía de su aspecto decorando la ropa con algún color (Baker, 1968). Asimismo, los colores han trascendido la esfera del esteticismo corporal y en la cultura oral de muchas sociedades se pone de relieve la importancia simbólica de los mismos (Classen, 1993). Desde los tiem- pos prehistóricos hasta la mitad del siglo XIX, el teñido fue hecho con colorantes naturales (Lock Sing de Ugaz, 1997). Con el paso de los años la tradición ancestral de teñir y colorear se ha debilitado. No sólo se ha perdido el uso de algunos recursos naturales con propiedades colorantes, sino también las técnicas o procedimientos de tinción (Flores \& Ling, 1990). En la actualidad los colorantes sintéticos han remplazado a la mayor parte de los naturales; sin embargo, se avizoran iniciativas que tienden de revalorizar los tintes tradicionales,

\footnotetext{
${ }^{1}$ Facultad de Ciencias Forestales, Universidad Nacional de Misiones. Instituto de Botánica del Nordeste, Casilla de Correo 209, 3400 Corrientes, Argentina.
} 
como es el caso de un grupo de artesanas de Los Toldos, provincia de Salta (Fabbio, Hilgert \& Lambaré, 2009). En algunos sitios de Europa se ha tomado la iniciativa de utilizar nuevamente tinturas tradicionales, debido a altos niveles de polución ambiental que causan los colorantes sintéticos (Lewington, 2003). Entre los pigmentos que la naturaleza ha ofrecido a las diferentes culturas del planeta, las plantas han ocupado y ocupan un lugar destacado, ofreciendo una gran diversidad de especies colorantes.

El catálogo de plantas vasculares de Misiones (www.darwin.edu.ar), permite estimar que la flora vascular de la provincia sobrepasa las 3000 especies. Muchos de estos taxones constituyen recursos que son o que podrían ser útiles para sus habitantes. La recolección de ejemplares de herbario en la actualidad incorpora a esta lista especies nuevas y nuevos registros para la flora local, los que gradualmente amplían el potencial de utilización de la vegetación, más aun considerando que muchos de estos registros refieren a plantas con usos múltiples (Keller, 2009a; Keller \& Tressens, 2007, 2008; Rodríguez \& al., 2009).

Los guaraníes habitan la provincia desde hace al menos 1200 años (Poujade, 1995), y han aprendido a utilizar los recursos florísticos que ofrecen los ecosistemas presentes en ella, selvas, humedales y campos naturales. Las parcialidades Mbya y Ava Chiripá, habitan gran parte de la región oriental del Paraguay, la provincia de Misiones en Argentina y el Sureste de Brasil, concordando con el área de distribución del Bosque Atlántico del Alto Paraná. Al igual que la mayor parte de los grupos pertenecientes al tronco lingüístico TupíGuaraní, estas parcialidades han desarrollado modos de subsistencia vinculados a la agricultura de roza y quema, cultivando una amplia diversidad de especies. En tiempos pretéritos, el complemento de proteínas se obtenía en su mayor parte de la caza y la pesca, pero actualmente la fauna ya no es tan abundante como para abastecer a las comunidades. La opresión causada por la sociedad global los ha obligado a adoptar otras modalidades de obtención de recursos, entre ellas el empleo transitorio, la comercialización de manufacturas artesanales y plantas ornamentales y la filiación a progra- mas ó proyectos de desarrollo. Los recursos aplicados en el ámbito de las actividades tradicionales, incluyendo el uso de colorantes han menguado debido al abandono de ciertas prácticas e indumentarias, pero algunas técnicas se han mantenido y han recobrado vigor mediante las nuevas estrategias de subsistencia, tales como la confección de artesanías.

El uso de especies vegetales por parte de estos grupos constituye un tema que ha sido tratado específicamente en varias publicaciones relativas a la Etnobotánica (Crivos et al., 2002; Gorosito Kramer, 1993; Keller, 2007, 2008a, 2009b, Keller \& Prance, 2008; Martinez Crovetto, 1968a, 1968b, 1980; Pochetino, 2007). En la presente contribución se aborda la categoría de uso relativa a las plantas capaces de brindar sustancias colorantes, las cuales han sido y son aprovechadas por ellos para llevar a cabo sus estrategias de subsistencia, constituyendo asimismo recursos también necesarios para desarrollar sus manifestaciones culturales tradicionales.

\section{Material y Métodos}

El trabajo de campo que ha permitido obtener información sobre esta y otras categorías de importancia de las plantas que conocen los guaraníes de la provincia de Misiones, se ha iniciado en el año 1998 y continúa en el presente. Se han efectuado visitas de duración variable a una veintena de comunidades localizadas en los departamentos Eldorado, Montecarlo, San Pedro, Guaraní, Lib. Gral. San Martín, San Ignacio y Concepción. En todos los casos se han efectuado visitas previas para explicar a los representantes de cada una de ellas, los objetivos del trabajo de campo, y en lo posible, establecer sinergias con proyectos o programas con los que ellos eventualmente se encuentren involucrados. Se han entrevistado a alrededor de cien informantes, de ambos sexos, diferentes edades, ocupaciones y posiciones dentro de la estructura comunitaria. El largo tiempo invertido en las campañas ha permitido aplicar diversas técnicas inherentes a los abordajes etnográficos, entrevistas estructuradas, semiestructuradas, observación participante y trabajos grupales. Al tratarse de 
una categoría de uso que se ha erosionado intensamente bajo la presión que ejercen los materiales que se adquieren del mercado, se han efectuado numerosas consultas a los ancianos, se han propiciado charlas retrospectivas sobre las especies empleadas y se han llevado a cabo actividades prácticas demostrativas con el fin de recrear algunas de las técnicas que han quedado en el pasado.

Se han recolectado ejemplares de herbario de las especies mencionadas, los mismos se hallan depositados en el herbario CTES, perteneciente al Instituto de Botánica del Nordeste (UNNE-CONICET) y el número de cada material de referencia se explicita en el apéndice.

\section{Resultados y Discusión}

La lengua guaraní es escasa en lo que respecta a la clasificación cromática, sin embargo ellos reconocen una gran diversidad de recursos naturales capaces de ofrecer pigmentos destinados a múltiples propósitos. En el apéndice se listan un total de 69 especies vegetales relacionadas al objetivo de esta contribución, muchas de las mismas son proveedoras de pigmentos, en cambio otras conforman los ingredientes necesarios para la obtención de productos colorantes.

En la actualidad los guaraníes emplean pigmentos naturales para pintarse el cuerpo en ocasiones especiales, pero es más frecuente el uso de los mismos para ornamentar manufacturas artesanales. La penetración de productos europeos eliminó tempranamente la producción autóctona del tejido y también de la cerámica, lo cual, como es de esperar, ha erosionado también las técnicas propias de la tintorería y de la ornamentación de cántaros. Sin embargo, ciertas prendas (adornos cefálicos y taparrabos) utilizadas hace no mucho tiempo por algunos líderes religiosos en ciertas ceremonias, ha permitido que se conserve en algunas personas el conocimiento sobre especies tintóreas usadas para colorear estos atuendos.

La amplitud de aplicaciones de las especies mencionadas permite clasificar a la categoría de uso de plantas colorantes en las tres subcategorías que se tratan a continuación.

\section{Colorantes corporales}

A lo largo del trabajo de campo se han recolectado evidencias que permitieron determinar cuatro razones por las cuales los guaraníes de ambas parcialidades se pintan, o en el pasado se han pintado partes del cuerpo; estas son: cosmética empleada para atraer al sexo opuesto o poner en evidencia interés por el mismo, protección espiritual durante determinadas etapas del ciclo vital, procedimientos mágicos y aplicaciones terapéuticas medicinales.

De acuerdo con testimonios recogidos en las comunidades, el uso de colorantes faciales de colores vivos, usados para atraer al sexo opuesto, pareciera haber sido patrimonio exclusivo de las mujeres, sin embargo en lo referente al tratamiento del cabello se han deslizado algunos comentarios sobre una aplicación actual que incluye a ambos sexos. La maceración de los brotes del bambú $M e$ rostachys clausseni Munro, en pocos minutos se ennegrece transformándose en una solución obscura. Esta es utilizada como enjuague capilar por los guaraníes que desean contrarrestar la decoloración causada por el paso del tiempo o por la exposición prolongada a los rayos solares. En la actualidad, la adquisición a bajo precio de tinturas para el pelo ha devenido en la proliferación de niños y jóvenes guaraníes ornamentados con mechones de cabello de colores vivos.

En el pasado las mujeres se pintaban los pómulos para denotar su condición de soltera en edad reproductiva. Aunque esta práctica denominada «ojegua» en la actualidad ya casi se ha extinguido, ha sido posible registrar una gran diversidad de recursos naturales que han sido empleados. Los colores destinados a tal fin son variados, y el modo de obtención más frecuente consiste en masticar ó restregar entre los dedos el material pigmentante impregnado con saliva, a veces con el agregado de extractivos tales como cenizas de madera. Las anteras de la gramínea Paspalum regnellii Mez. (Fig. 1A) recolectadas en cantidad suficiente, ofrecen un color morado, similar al de los frutos 

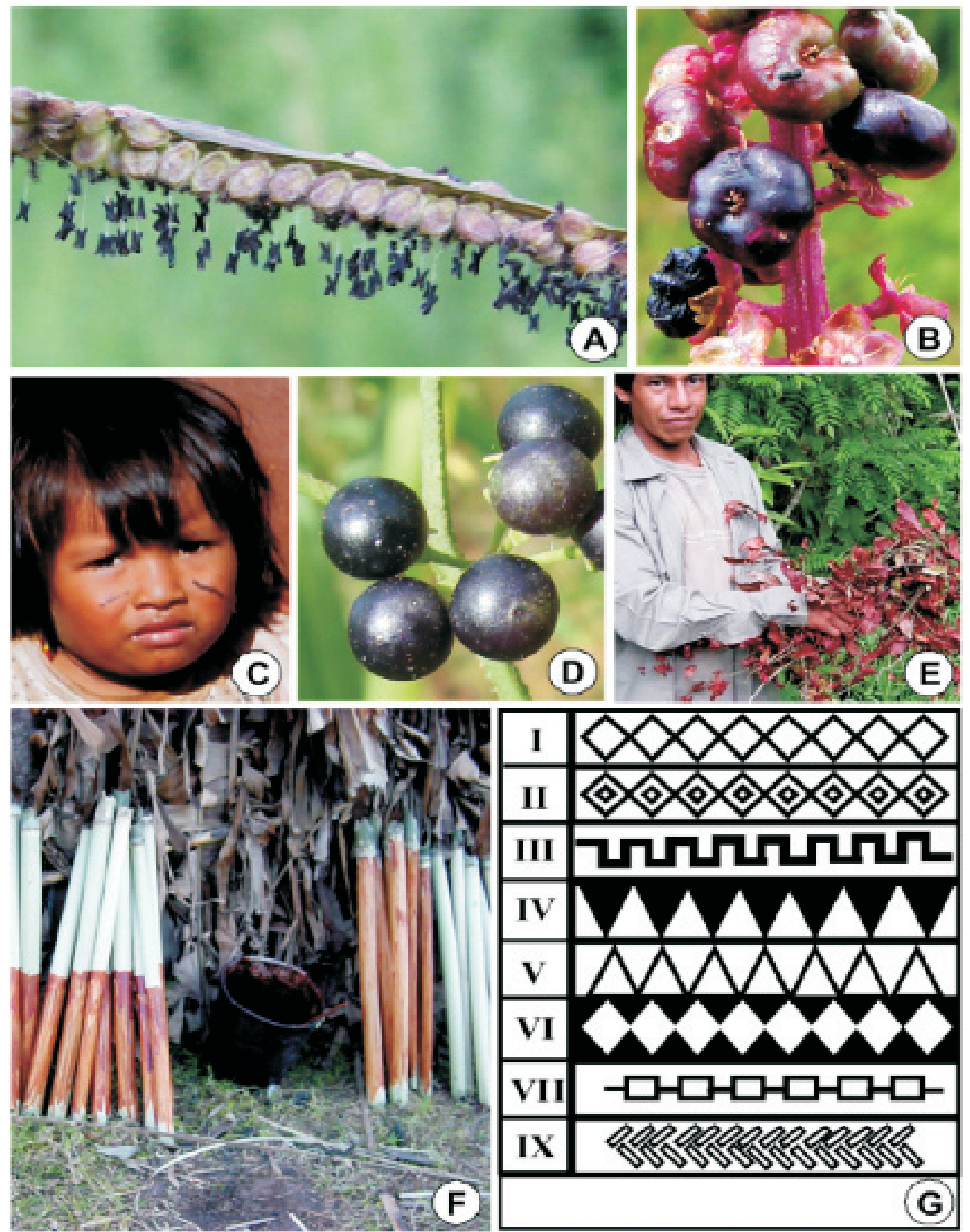

Fig. 1. Plantas colorantes. A: anteras de Paspalum regnellii Mez (Poaceae). B: frutos de Phytolacca thyrsiflora Fenzl ex J. A. Schmidt (Phytolaccaceae). C: niña mbya con pintura facial de protección. D: frutos de Solanum americanum Mill. (Solanaceae). E: joven guaraní con hojas secas de Arrabidaea chica (Humb. \& Bonpl.) Verl. (Bignoniaceae). F: tallos de bambú recién pintados. G: diseños que ornamentan las artesanías: «yarara» (I), «mbói chini» (II), «ñacanina» (III), «piraju ra)» (IV), «tape pepo» (V), «tanambi pepo» (VI) «cadena» (VII) y «zanello» (VIII). 
de la palmera Euterpe edulis Mart. Ciertas fitolacáceas con frutos jugosos ofrecen tintes de rápida aplicación, dos especies de Phytolacca L. (Fig. 1B) permiten colorear pómulos de rojo-violáceo, en tanto los frutos de Rivina humilis L. dan un color anaranjado similar a la tintura de yodo que se obtiene en el comercio como antiséptico. Los rojizos talos del liquen Cryptothecia rubrocincta (Ehrenb. Fr.) Thor (Arthoniaceae), liberan un color azul intenso luego de unos minutos de ser masticados. Las hojas de Hyptis althaefolia Pohl ex Benth. (Lamiaceae) y de Eupatorium caaguazuense Hieron. (Asteraceae), luego de unos instantes de esmerada fricción manual liberan una sustancia de color amarronada. En algunas aldeas se cultivan ejemplares de Morus alba L. (Moraceae) para dar sombra a los patios, las niñas guaraníes para divertirse suelen a veces pintarse las manos y el rostro con sus frutos morados.

Los guaraníes emplean una gran cantidad de plantas como talismanes amorosos ó que forman parte de procedimientos mágicos para atraer al sexo opuesto (Martínez Crovetto, 1980). Se ha observado que la mayoría de las especies que se usan para este fin contienen sustancias aromáticas y/o colorantes. Por esta razón, aunque actualmente no todos los procedimientos de su aplicación aprovechen estas cualidades, es viable conjeturar que el uso de plantas para enamorar quizá se haya desarrollado a partir de una intención primigenia más vinculada a la cosmética y la perfumería que a los supuestos poderes mágicos de las especies. Como ejemplo se puede mencionar el testimonio de un joven informante quien ha referido el empleo de ramitas de Solanum hirtellum (Spreng.) Hassl. (Solanaceae) para atraer a las mujeres a su vivienda, el procedimiento que él recomienda consiste en colocar dicho material sobre un receptor de radio mientras se escucha música a todo volumen. Por otra parte y en referencia al uso de esta misma especie para enamorar a los hombres, una anciana expuso un procedimiento consistente en desmenuzar sus pequeños frutos para pintarse los pómulos, esta acción además de ofrecer un color morado libera una intensa fragancia. Informantes masculinos, sin saber dar detalles procedimentales explicaron el uso de ciertas especies de Pavo- nia Cav. (Malvaceae) por parte de las mujeres que desean enamorar a sus pretendidos. Más tarde se pudo obtener información sobre este asunto, en la que se detalla el uso como colorante facial de los pétalos de estas plantas, los que restregados intensamente liberan un color amarillo. Un caso similar se presenta con las raíces anaranjadas o rojizas, o los frutos azules de especies de rubiáceas, que hoy en día se emplean en diversos procedimientos mágicos de seducción, muchas veces alejados de su función colorante original.

Además del solvente acuoso que implica el empleo de la saliva, un anciano mencionó el uso del látex obtenido de ciertas especies de plantas trepadoras, el cual mezclado con aserrín de la madera colorida de ciertos árboles, permitía a las mujeres de piel más oscura obtener coloretes que contrastaban mejor con su tez. Entre estos árboles se ha mencionado a Cabralea canjerana (Vell.) Mart. (Meliaceae) con leño rojo obscuro; Maclura tinctoria (L.) Steud (Moraceae) con madera de color amarillo intenso; especies del género Prunus L. (Rosaceae) de color anaranjado.

Martínez Crovetto (1968c) menciona el cultivo del árbol con frutos colorantes Bixa orellana L. (Bixaceae) en comunidades guaraníes de Misiones. Si bien esto no se ha observado en la actualidad, varios ancianos recuerdan esta especie, y en reiteradas ocasiones han solicitado la adquisición de semillas o plantas para cultivarlas nuevamente y poder ornamentar el rostro de los niños que se presentan a eventos sociales en los cuales despliegan sus canciones tradicionales. Algunos guaraníes inmigrantes que provienen del Paraguay, mencionan el empleo como colorante facial azul de los frutos de Genipa americana L. (Rubiaceae), no obstante en Misiones sólo se han hallado ejemplares cultivados.

En las comunidades guaraníes más conservadoras, es aún frecuente observar niños con trazos oscuros pintados en el rostro, esta circunstancia se presenta cuando en el núcleo familiar de los mismos hay niños recién nacidos. Al mismo tiempo la madre se pinta líneas negras en los codos y las rodillas y el padre los tobillos. Estas pinturas negras son también usadas durante la etapa de iniciación de los jóvenes y están relacionadas con la protección 
del individuo ante el acecho de entidades sobrenaturales (por ejemplo espíritus de jaguares y duendes lascivos). Durante estas etapas del ciclo vital se toman además una gran cantidad de recaudos, tales como, la prohibición de la ingesta de carne, el enjuague diario con maceraciones aromáticas y la reclusión temporal. Es muy probable que estas prácticas preventivas hayan tenido su origen en tiempos pretéritos, cuando las circunstancias obligaban a ocultar a los más indefensos, tratar de hacerlos pasar desapercibidos ante los predadores naturales o las hordas acechantes de otras etnias. En estas ocasiones, la pintura corporal obscura pudo haber cumplido una función pragmática de camuflaje o encubrimiento, función que en la actualidad se halla asignada a prácticas más inherentes al plano espiritual. Las pinturas de protección se elaboran con propóleo de una especie de melipónido denominado «jate'i», mezclado con hojas carbonizadas y pulverizadas del bambú Chusquea ramosissima Lindm. El resultado es un pequeño cilindro de textura similar a la cerámica cruda llamado «ychy». Antes de ser usado se entibia un extremo del mismo aproximándolo al fuego hasta que se funde parcialmente, permitiendo de esta manera el trazado de figuras que se consolidan al instante, cuando el fluido obscuro se enfría y se solidifica, permitiendo una duración de varias semanas.

Se han documentado diversos diseños de pinturas faciales entre los guaraníes, casi siempre asociándolos a la simple ornamentación (Ambrosetti, 1895; Hanke, 1995). En las aldeas visitadas, se han observado trazos simples en los pómulos (Fig. 1C), pero también los informantes han referido a otros diseños como «akuchi rai» (dientes del roedor agutí) consistente en dos líneas paralelas en cada pómulo que se aplicaban los hombres solteros. Se denomina «ojẽgua piriri» (ornamento punteado) a un diseño con cinco puntos dispuestos de manera circular. Las mujeres solteras enunciaban su condición mediante el diseño «araku pycha» (dedos del ave saracura) consiste en tres líneas radiales (similares a una huella de ave) ubicadas en cada pómulo más una cruz situada en la frente. El diseño «urukure'a» (una especie de búho), consiste en pintarse trazos semicirculares debajo de los ojos, a modo de ojeras. Un círculo lleno entre los ojos es un diseño usado tradicionalmente por hombres que recibía la denominación de «uru repochy» (estiércol del ave uru). Ambrosetti (1895) menciona el hecho de que los diseños pintados en un pómulo siempre se replican en el otro; sin embargo un informante explicó que los hombres y mujeres casados, con el fin de manifestar su condición conyugal se pintaban solamente un lado de la cara.

Las pinturas corporales también tienen diseños con fines terapéuticos, el mismo marcador «ychy» usado para la protección espiritual, también es empleado para extraer espinas incrustadas bajo la piel o para tratar el reumatismo o las afecciones articulares en general. Para tratar el sarampión, los guaraníes se valen de frutos de colores violáceos con cuyos epicarpios tiñen las erupciones de la piel que se suscitan durante esta enfermedad. Entre las especies proveedoras de estos frutos se ha mencionado a Ilex paraguariensis A.St.-Hil. (Aquifoliaceae); Sambucus australis Cham. \& Schltdl. (Caprifoliaceae) y Solanum americanum Mill. (Solanaceae) (Fig. 1D).

El empleo de sustancias colorantes también se aplica a procedimientos mágicos. Como ejemplo se puede citar el uso de frutos de especies del género Rubus (Rosaceae) con los cuales guaraníes se pintan los brazos antes de una jornada de caza, con el objetivo de ser más certeros en el lanzamiento de proyectiles (flechas, municiones, piedras, etc). Estas especies son denominadas «temby'aja» (dueño del acierto) por los Mbya, y «juka katu» (para matar) por los Ava Chiripa.

\section{Colorantes de artesanías y otras manufac- turas}

Los guaraníes elaboran artesanías que ofrecen a la venta en las ciudades o en puestos de venta situados en las márgenes de rutas asfaltadas. Estas artesanías consisten en cestos, tapices, collares y tallas en madera. Un modo frecuente de colorear la cestería o los tapices consiste en alternar las bandas de las bambúseas usadas en el entretejido con cintas de corteza de las raíces de Philodendron bipinnatifidum Schott. ex Endl. (Araceae), que ofrecen un color pardo rojizo. Otras veces se 
deja la capa superficial fotosintética de las bandas de bambú que se van a entretejer, para obtener diseños verde-pálidos sobre un fondo más claro. Sin embargo es más frecuente el empleo de una pintura rojiza elaborada fundamentalmente con corteza de Trichilia catigua A. Juss. (Meliaceae), la cual mediante raspado con machete es obtenida en forma de viruta. Estas astillas laminares se hierven utilizando cenizas de ciertas especies arbóreas, que permiten una mayor extracción del color y espesan la solución. El agregado del parénquima mucilaginoso de los tallos de ciertas especies de cactáceas, permite aglutinar el fluido y tornarlo más adherente. Algunos informantes refieren el empleo de cenizas de diferentes especies de árboles para que este colorante adquiera matices y tonalidades diferentes, las cenizas de especies de Prunus (Rosaceae) lo tornan amarillo, las de Vitex megapotamica (Spreng.) Moldenke (Verbenaceae) marrón obscuro. Se usan también cortezas de otras especies como sucedáneas o para obtener colores alternativos, la de Plinia rivularis (Cambess.) Rotman (Myrtaceae) y la de Fagara naranjillo (Griseb.) Engl., brindan una coloración verde oliva; la de Patagonula americana L. (Boraginaceae) dan un color marrón. Con las hojas de la trepadora Arrabidaea chica (Humb. \& Bonpl.) Verl. (Bignoniaceae) disecadas al sol (Fig. 1E), es posible elaborar un colorante rojo-vinoso.

Cuando desean ornamentar la cestería con diseños negros los guaraníes utilizan marcadores del propóleo de un melipónido, mezcladas con tallos u hojas carbonizadas de distintas especies, especialmente bambúes y especies leñosas de madera blanda como ser Nectandra megapotamica (Spreng.) Mez (Lauraceae); Sapium glandulosum (L.) Morong (Euphorbiaceae); Trema micrantha (L.) Blume (Celtidaceae); entre otras.

El material de bambú que se va a colorear es raspado para eliminar una capa superficial fotosintética y áspera al tacto, luego es expuesto al aire por unos días hasta que se seque y entonces es pincelado con el fluido colorante. Muchas veces este procedimiento es llevado a cabo antes de la separación de las bandas que se van a entretejer, como puede apreciarse en la Fig. 1F.
Las figuras que decoran la cestería conforman diferentes diseños, algunos de los cuales en el pasado seguramente han adornado los cántaros y los atuendos tradicionales. En general las denominaciones de los diseños hacen referencia a su semejanza con elementos de la naturaleza. Entre los más comunes cabe mencionar los siguientes que se ilustran en la Fig. 1G: «yarara» (serpiente del género Bothrops); «mbói chini» (serpiente de cascabel); «ñacanina» (una culebra del género Mastigodryas); «piraju rai» (dientes del pez dorado); «tape pepo» (alas del milano tijereta); «tanambi pepo» (alas de mariposa). También han incorporado representaciones nuevas a partir de la observación de elementos foráneos a su cultura; irónicamente estos diseños están vinculados a la explotación de la selva por parte de propietarios y compañías, los cual ha llevado a su hábitat natural casi al borde del exterminio. Estos diseños son «cadena» (usadas en las maquinarias forestales para arrastrar troncos) y «zanello» (una marca de moto-arrastradora forestal articulada).

Los guaraníes labran figuras de animales $\mathrm{y}$ otras representaciones en maderas duras y blandas de diferentes especies arbóreas. Por lo general el modo de colorear estas artesanías consiste en quemar la superficie del leño empleando una varilla de hierro o un cuchillo al rojo vivo. Ocasionalmente labran los nudos cónicos presentes en la inserción de las ramas laterales de Araucaria angustifolia (Bertol.) Kuntze (Araucariaceae), este material leñoso contiene una resina de color rojo que fluye de la superficie que se calienta al fuego, lo que permite en pocos segundos barnizar de rojo traslúcido una pieza ya labrada.

\section{Tintorería}

Salvo muy raras excepciones relativas a aplicaciones ceremoniales, los guaraníes de Misiones ya no confeccionan géneros de ningún tipo. Hasta hace un par de décadas, líderes religiosos y políticos aún lucían bandas cefálicas, e inclusive taparrabos en ceremonias y reuniones entre comunidades. Las bandas cefálicas de los Ava Chiripá se elaboran con una tira de corteza de un árbol de la familia de las rutáceas, esta se tiñe con un extracto del 
liquen Cryptothecia rubrocincta (Ehrenb. Fr.) Thor (Arthoniaceae); y se adorna con plumas de tucanes y otras aves.

Para teñir los atuendos los ancianos afirman que empleaban muchos de los colorantes mencionados para las pinturas corporales y para la cestería; destacan la combinación de cortezas y el agregado de cenizas que permitía obtener variaciones de matices. También se menciona el uso de pigmentos obtenidos a partir de frutos, coincidiendo estos con los de las especies antes mencionadas y también otros de especies de la familia Myrtaceae. En cuanto a la durabilidad del color de la tintura para telas, varios informantes coincidieron en que el que más resiste al desgaste es el obtenido de las hojas de Arrabidaea chica (Humb. \& Bonpl.) Verl. (Bignoniaceae).

Aunque no es frecuente en la actualidad, el transporte de pertenencias en bolsas de pieles ha sido documentado para los guaraníes (Metraux, 1948). Martínez Crovetto, en sus notas de campo inéditas registró para los Mbya de Misiones el uso de Maclura tinctoria (L.) Steud. (Moraceae) para colorear cueros de rojo y amarillo.

Se ha entrevistado en Misiones a inmigrantes del Paraguay, mestizos entre criollos y guaraníes, ellos mencionan al «ysypo ju» (apoyante amarilla), como una hierba palustre cuyas raíces anaranjadas han sido utilizadas para colorear manufacturas textiles de amarillo obscuro y también para pigmentar la grasa bovina fundida. La literatura de Paraguay menciona bajo esta denominación a Escobedia grandiflora (L. f.) Kuntze (Scrophulariaceae) (Gonzáles Torres, 1991). La presencia de esta especie en Misiones, Argentina, no ha sido del todo confirmada debido a la inexactitud geográfica de las leyendas en los rótulos de colección de material de herbario (Rossow, 1983).

\section{Conclusiones}

Los resultados obtenidos permiten visualizar que las plantas colorantes conforman una categoría de utilización de recursos natura- les que entre los guaraníes se ha erosionado tempranamente dentro de ciertas aplicaciones específicas (cosmética, tinturas para telas) y se ha adaptado, desarrollado y estabilizado para otras (artesanías, protección espiritual). Asimismo, se sugiere aquí que el uso pretérito de plantas en la cosmética amorosa de los guaraníes, pervive en la aplicación de las mismas especies como talismanes para atraer al sexo opuesto, aunque los procedimientos actuales no siempre involucren el usufructo de sus cualidades colorantes o aromatizantes.

En trabajos precedentes se asocia la intención de las pinturas faciales guaraníes sólo a la ornamentación, en cambio los resultados expuestos en el acápite de colorantes corporales amplían las categorías de su empleo y permiten reflexionar sobre dos objetivos contrapuestos, el ocultamiento y la exhibición, en los cuales los colores empleados alcanzan una notoriedad simbólica muy definida y asociada a la actitud de una presa ante el predador. Los colores obscuros, asociados a la noche, son empleados para ocultar a las personas susceptibles al acecho de espíritus salvajes tales como jaguares y duendes lascivos; en cambio los colores vivos como el rojo y el morado, asociados a la carne y a la sangre, son usados para atraer.

Otro hecho notable es la incorporación de los diseños nuevos en la ornamentación de artesanías, algunos de los cuales están asociados a las maquinarias que usan los «blancos» para efectuar la explotación comercial de la selva. Esto pone de manifiesto la capacidad de usufructuar circunstancias desfavorables.

Finalmente cabe destacar que el intenso y prolongado trabajo de investigación en campo ha permitido documentar una gran diversidad de plantas y formas de uso para esta categoría, sin embargo muchos de los colorantes naturales y de las técnicas de coloración que se mencionan en la presente contribución son actualmente conocidas sólo por unos pocos ancianos. Ello permite reafirmar que la labor Etnobotánica cumple un rol importante contribuyendo a la preservación del conocimiento de los recursos naturales autóctonos. 


\section{Agradecimientos}

A los miembros de las comunidades guaraníes visitadas. A Antonio Krapovickas y Teresa de Arguelles de Andrés pos su asesoramiento bibliográfico. A los especialistas del Instituto de Botánica del Nordeste (UNNE-CONICET) que han colaborado con la identificación del material de herbario.

\section{Bibliografía}

AMBROSETTI, J. B. 1895. Los indios Cainguá del Alto Paraná. Bol. Inst. Geográf. 15: 661-744.

BAKER, H. G. 1968. Las plantas y la civilización. Serie Fundamentos de Botánica. Ed. Herrero Hermanos Sucesores S.A., México, 193 pp.

CRIVOS, M., M. R. MARTÍNEZ \& M. L. POCHETTINO. 2002. El aporte etnográfico en estudios interdisciplinarios acerca de la relación hombre-entorno natural (comunidades Mbyá-Guaraní, provincia de Misiones, Argentina). Etnobiología 2: 76-89.

FABBIO, F. A.; N. I. HILGERT \& D. A. LAMBARÉ. 2009. Los tintes naturales de Los Toldos y alrededores. $1^{\circ}$ Ed. CYTED-RISAPRET, San Salvador de Jujuy, 90 pp.

FLORES, L. \& F. LING. 1990. Artesanía en Talamanca: El Sémko y los Colorantes Naturales. CATIE. Turrialba, CR. 7 pp.

GONZALES TORRES, D. 1991. Cultura Guaraní. Ed. Instituto Superior de Lenguas. Facultad de Filosofía, Universidad de Asunción, Asunción, 269 pp.

GOROSITO KRAMER, A. M. 1993. Clasificaciones y prácticas aborígenes. Proyecto Plantas medicinales, Área Guaraní. Informe de Investigación, VII Jornadas Técnicas: «Ecosistemas forestales nativos». I.S.I.F. UNAM, Eldorado: 330-361.

HANKE, W. 1995. Dos años entre los Cainguá. Ed. Centro Argentino de Etnología Americana. Buenos Aires, $101 \mathrm{pp}$.

KELLER, H. A. 2007. Notas sobre medicina y magia entre los guaraníes de Misiones, Argentina, un enfoque etnobotánico. Suplemento Antropológico de la Universidad Católica de Asunción 42 (2): 345-384. 2008. Las plantas usadas en la construcción de viviendas y templos guaraníes en Misiones, Argentina. Bonplandia 17(1-2): 65-81.

. 2009a. La presencia en Argentina de Berberis laurina Billb. (Berberidaceae), una especie de uso múltiple. Kurtziana 34(1): 1-5.

2009b. Plantas textiles de los guaraníes de Misiones (Argentina). Bonplandia 18(1): 29-37.

\& G. T. PRANCE. 2008. Plants associated with fish by Guaraníes of Misiones, Argentina. Ethnobotany 20:1-8.

— \& S.G. TRESSENS. 2008. Primer registro para la Argentina de dos especies de uso medicinal. Bol. Soc. Argent. Bot. 43 (1-2): 171-178.

- 2007. La presencia en Argentina de dos especies de uso múltiple. Acca sellowiana (Myrtaceae) y Casearia lasiophylla (Flacourtiaceae). Darwiniana 45(2): 204-212.

LEWINGTON, A. 2003. Plants for People. Eden Project Books, Cornwal, U.K. 304 pp.

LOCK SING DE UGAZ, O. 1997. Colorantes naturales. Fondo Editorial Pontificia Universidad Católica del Perú, Lima. 274 p.

MARTÍNEZ CROVETTO, R. N. 1968a. La alimentación entre los indios guaraníes de Misiones. Etnobiológica 4: 1-24.

1968b. Juegos y deportes de los indios guaraníes de Misiones. Etnobiológica.6:1-30.

- 1968c. Notas sobre la agricultura de los indios guaraníes de Misiones. Etnobiológica 10: 1-11. 1980. Plantas mágicas de los indios guaraníes de Misiones (República Argentina). La Antropología Americanista en la Actualidad, 2: 455-463

METRAUX, A. 1948. The Guaraní. In Handbook of South American Indians, III. Washington.

POCHETTINO, M. L. 2007. Recolección y comercialización de plantas silvestres en dos comunidades Mbya-Guaraní (Misiones, Argentina). Kurtziana 33 (1): 27-38.

POUJADE, R.A. 1995. Mapa arqueológico de la provincia de Misiones (Cartilla explicativa). Artes gráficas Zamphirópolos S.A., Asunción. p. 7-8.

ROSSOW, R. A. 1983. Notas sobre Scrophulariaceae. Parodiana 2: 117-130.

RODRÍGUEZ, M. E.; A. E. CARDOZO; E. R. KRAUCZUK; J. L. FONTANA \& D. IRIART. 2009. $\mathrm{Ca}$ lophyllum brasiliense (Clusiaceae), nuevo registro para la flora argentina. Bol. Soc. Argent. Bot. 44 (3-4): 361-366.

Original recibido el 11 de febrero de 2010; aceptado el 19 de abril de 2010. 
Apéndice: Lista de especies empleadas o relacionadas a la obtención de colorantes de los guaraníes: se detalla el nombre guaraní, el uso, la parte usada y un ejemplar testigo del herbario CTES recolectado por Keller ó Keller \& al.; Departamentos: C: Concepción; E: Eldorado; G: Guaraní; I: Iguazú, L: Libertador General San Martín; M: Montecarlo; MB: Gral. Manuel Belgrano; S: San Pedro y SI: San Ignacio.

\begin{tabular}{|c|c|c|c|c|}
\hline ESPECIE & NOMBRE & USO & PARTE & TESTIGO \\
\hline
\end{tabular}

SPERMATOPHYTA-

ANGIOSPERMAE

\section{MONOCOTYLEDONEAE}

Araceae

Philodendron bipinnatifidum guembe

Motivo de cestería

Corteza de la

$1432(\mathrm{M})$

Schott. ex Endl.

raíz aérea

Arecaceae

Arecastrum romanzoffianum pindo

(Cham.)Becc.

Hospedante de liquen tintóreo

Estípite

$1482(\mathrm{~L})$

Euterpe edulis Mart.

jejy

Colorante facial (mo-

Frutos

$621(\mathrm{M})$ rado). Tintura para tela

Orchidaceae

Catasetum fimbriatum (C. mbaraka poa Morr.) Lindl. Ex Paxton

kuña

Aglutinante para pinturas

Pseudobulbos

$1433(\mathrm{~S})$

Cyrtopodium palmifrons

mbaraka poa $\mathrm{y}$ barnices

ava

Aglutinante para pinturas

Pseudobulbos

$3385(\mathrm{G})$

Rchb. f. et Warm. y barnices

\section{Poaceae}

Chusquea ramosissima

Lindm.

Merostachys clausseni

Munro takuapi Colorante para teñir el

ñanderopy ova cabello. Colorante de
Colorante corporal (negro) con fines tera-

(mb) ene kyche (ch)

péuticos y de protección espiritual. Colorante de cestería (negro) cestería (negro).
Tallos y hojas

carbonizadas

Yemas apicales. $317(\mathrm{~L})$

Hojas carbon-

izadas 


\begin{tabular}{llll}
\hline ESPECIE & NOMBRE & PARTE & TESTIGO \\
\hline
\end{tabular}

Asteraceae

Eupatorium caaguazuense pirincho ka'a Colorante facial (marrón) Hojas

$8277(\mathrm{SI})$

Hieron.

Apocynaceae

Condylocarpon isthmicum ychypo kamby

Base para pintura facial

Látex

$1064(\mathrm{G})$

(Vell.) A.DC.

femenina

Forsteronia glabrescens Müll. ychypo kamby

Base para pintura facial

Látex

$7551(\mathrm{SI})$

Arg.

femenina

Peltastes peltatus (Vell.) ychypo kamby

Base para pintura facial

Látex

femenina

Woodson

Bignoniaceae

Arrabidaea chica (Humb. \& ychypo pytã u

Colorante de cestería

Hojas

448 (E)

Bonpl.) Verl.

(rojo vinoso)

Bixaceae

Bixa orellana L.

uruku

Colorante facial (rojo)

Frutos (apoca-

8279 (E) rotenoide,

bixina)

Boraginaceae

Patagonula americana L.

guajayvi

Colorante facial (negro).

Leño pulver-

7694 (SI)

Colorante de cestería

izado. Corteza

(marrón).

\section{Cactaceae}

Cereus stenogonus K.

Schum.

jakare ruguái

rã (ch)

y'i apipe (ch)

Opuntia arechavalatae Speg. tuna
Aglutinante de pinturas Mucílago para cestería

$3020(\mathrm{G})$

Aglutinante de pinturas Mucílago

$2003(\mathrm{G})$ para cestería 


\begin{tabular}{|c|c|c|c|c|}
\hline ESPECIE & NOMBRE & USO & PARTE & TESTIGO \\
\hline $\begin{array}{l}\text { Lonchocarpus campestris } \\
\text { Mart. ex Benth. }\end{array}$ & yvyra kachi & $\begin{array}{l}\text { Colorante facial (marrón). } \\
\text { Espesante de pintura para } \\
\text { cestería }\end{array}$ & $\begin{array}{l}\text { Leño pulver- } \\
\text { izado. Cenizas } \\
\text { del leño }\end{array}$ & 7742 (SI) \\
\hline $\begin{array}{l}\text { Pelthophorum dubium } \\
\text { (Spreng.) Taub. }\end{array}$ & yvyra pytã & $\begin{array}{l}\text { Espesante de pintura para } \\
\text { cestería }\end{array}$ & $\begin{array}{l}\text { Cenizas del } \\
\text { leño }\end{array}$ & 7769 (SI) \\
\hline \multicolumn{5}{|l|}{ Lamiaceae } \\
\hline $\begin{array}{l}\text { Hyptis althaefolia Pohl ex } \\
\text { Benth }\end{array}$ & chirka & $\begin{array}{l}\text { Colorante facial (ama- } \\
\text { rillo-rojizo) }\end{array}$ & Hojas & $6047(\mathrm{C})$ \\
\hline \multicolumn{5}{|l|}{ Lauraceae } \\
\hline $\begin{array}{l}\text { Nectandra megapotamica } \\
\text { (Spreng.) Mez }\end{array}$ & $\begin{array}{l}\text { aju'y pytã (ch), } \\
\text { aju'y u (mb) }\end{array}$ & $\begin{array}{l}\text { Colorante de cestería } \\
\text { (negro) }\end{array}$ & $\begin{array}{l}\text { Leño carbon- } \\
\text { izado }\end{array}$ & $8293(\mathrm{MB})$ \\
\hline \multicolumn{5}{|l|}{ Malvaceae } \\
\hline $\begin{array}{l}\text { Pavonia communis A. St.- } \\
\text { Hil. }\end{array}$ & kuña manje'a & $\begin{array}{l}\text { Colorante facial (ama- } \\
\text { rillo) }\end{array}$ & Pétalos & $6428(S)$ \\
\hline Pavonia sepium A. St.-Hil. & mbutuk a'a & $\begin{array}{l}\text { Colorante facial (ama- } \\
\text { rillo) }\end{array}$ & Pétalos & $191(\mathrm{MB})$ \\
\hline $\begin{array}{l}\text { Pavonia subrotunda A. St.- } \\
\text { Hil. \& Maudin }\end{array}$ & ka'avo chiripa & $\begin{array}{l}\text { Colorante facial (ama- } \\
\text { rillo) }\end{array}$ & Pétalos & $5802(\mathrm{SI})$ \\
\hline \multicolumn{5}{|l|}{ Meliaceae } \\
\hline $\begin{array}{l}\text { Cabralea canjarana (Vell.) } \\
\text { Mart. }\end{array}$ & $\begin{array}{l}\text { poã ruvicha, } \\
\text { yvyra ruvicha }\end{array}$ & Colorante facial (rojo) & $\begin{array}{l}\text { Leño pulver- } \\
\text { izado }\end{array}$ & $1886(\mathrm{~S})$ \\
\hline Trichilia catigua A. Juss. & kachygua & $\begin{array}{l}\text { Colorante de cestería. } \\
\text { Tintura para tela (rojizo) }\end{array}$ & Corteza & $272(\mathrm{~S})$ \\
\hline Trichilia clauseni C.DC. & yvyra chanto & $\begin{array}{l}\text { Colorante de cestería } \\
\text { (rojizo) }\end{array}$ & Corteza & $6488(\mathrm{G})$ \\
\hline
\end{tabular}

Moraceae 


\begin{tabular}{|c|c|c|c|c|}
\hline ESPECIE & NOMBRE & USO & PARTE & TESTIGO \\
\hline Eugenia uniflora L. & ñangapiri & Tintura para tela (roja) & Frutos & \\
\hline $\begin{array}{l}\text { Plinia rivularis (Cambess.) } \\
\text { Rotman }\end{array}$ & guaporaity & $\begin{array}{l}\text { Colorante de cestería } \\
\text { (verde oliva). Tintura } \\
\text { para tela (morada) }\end{array}$ & Corteza. Frutos & $273(\mathrm{~S})$ \\
\hline $\begin{array}{l}\text { Plinia trunciflora (O. Berg.) } \\
\text { Kausel }\end{array}$ & yvapuru & Tintura para tela (morada) & Frutos & $3378(\mathrm{G})$ \\
\hline Phytolaccaceae & $\sim$ & & & \\
\hline $\begin{array}{l}\text { Phytolacca bogotensis } \\
\text { H.B.K. }\end{array}$ & $\begin{array}{l}\operatorname{arao}(\mathrm{mb}) \text { ombu } \\
\operatorname{miri}(\mathrm{ch})\end{array}$ & $\begin{array}{l}\text { Colorante facial. Colo- } \\
\text { rante de cestería. Tintura } \\
\text { para tela (rojo-violáceo) }\end{array}$ & Frutos & $2090(\mathrm{~S})$ \\
\hline $\begin{array}{l}\text { Phytolacca thyrsiflora Fenzl } \\
\text { ex J. A. Schmidt }\end{array}$ & $\operatorname{arao}(\mathrm{mb})$ & $\begin{array}{l}\text { Colorante facial (rojo- } \\
\text { violáceo) }\end{array}$ & Frutos & $8287(\mathrm{MB})$ \\
\hline Rivina humilis L. & yvyra apyta & $\begin{array}{l}\text { Colorante facial (rojizo). } \\
\text { Tintura para tela }\end{array}$ & Frutos & $342(\mathrm{M})$ \\
\hline \multicolumn{5}{|l|}{ Rosaceae } \\
\hline Prunus chamissoana L. & yvaro & $\begin{array}{l}\text { Colorante facial (anaran- } \\
\text { jado).Tornar más amarilla } \\
\text { a pintura de cestería }\end{array}$ & $\begin{array}{l}\text { Leño pulver- } \\
\text { izado. Cenizas } \\
\text { del leño }\end{array}$ & $1930(\mathrm{G})$ \\
\hline $\begin{array}{l}\text { Prunus subcoriacea (Chodat } \\
\& \text { Hassl.) Koehne }\end{array}$ & yvaro & $\begin{array}{l}\text { Colorante facial (anaran- } \\
\text { jado).Tornar más amarilla } \\
\text { a pintura de cestería }\end{array}$ & $\begin{array}{l}\text { Leño pulver- } \\
\text { izado. Cenizas } \\
\text { del leño }\end{array}$ & $2077(\mathrm{~S})$ \\
\hline Rubus rosifolius Baker & temby'aja (mb) & $\begin{array}{l}\text { Pintura corporal } \\
\text { (roja)usada en proced- } \\
\text { imiento de magia }\end{array}$ & Frutos & $2132(\mathrm{E})$ \\
\hline Rubus schotti Pohl ex Focke & $\begin{array}{l}\text { juka katu (ch) } \\
\text { temby'aja (mb) }\end{array}$ & $\begin{array}{l}\text { Pintura corporal (roja) } \\
\text { usada en procedimiento } \\
\text { de magia }\end{array}$ & Frutos & $913(\mathrm{E})$ \\
\hline $\begin{array}{l}\text { Rubus sellowii Cham. \& } \\
\text { Schltdl. }\end{array}$ & $\begin{array}{l}\text { juka katu (ch) } \\
\text { temby'aja (mb) }\end{array}$ & $\begin{array}{l}\text { Pintura corporal } \\
\text { (roja)usada en proced- } \\
\text { imiento de magia }\end{array}$ & Fruto & $1880(\mathrm{~S})$ \\
\hline
\end{tabular}




\begin{tabular}{|c|c|c|c|c|}
\hline ESPECIE & NOMBRE & USO & PARTE & TESTIGO \\
\hline $\begin{array}{l}\text { Galium megapotamicum } \\
\text { Spreng. }\end{array}$ & anguja ka'a & $\begin{array}{l}\text { Colorante facial (anara- } \\
\text { njado) }\end{array}$ & Raíces & $5605(\mathrm{C})$ \\
\hline $\begin{array}{l}\text { Galium nigroramosum (Eh- } \\
\text { rend.) Dempster }\end{array}$ & memejo & $\begin{array}{l}\text { Colorante facial (anara- } \\
\text { njado) }\end{array}$ & Raíces & $223(\mathrm{G})$ \\
\hline $\begin{array}{l}\text { Galium richardianum (Gillies } \\
\text { ex Hook. \& Arn.) Endl. ex } \\
\text { Walp. }\end{array}$ & anguja ka'a & $\begin{array}{l}\text { Colorante facial (anara- } \\
\text { njado) }\end{array}$ & Raíces & $2173(\mathrm{E})$ \\
\hline $\begin{array}{l}\text { Galium hypocarpium (L.) } \\
\text { Endl. ex Griseb. }\end{array}$ & anguja ka'a & $\begin{array}{l}\text { Colorante facial (anara- } \\
\text { njado) }\end{array}$ & Raíces & $1270(\mathrm{SI})$ \\
\hline $\begin{array}{l}\text { Psychotria leiocarpa Cham. } \\
\text { et Schltdl. }\end{array}$ & tapichi ka'a & Colorante facial (azul) & Frutos & $1856(\mathrm{~S})$ \\
\hline $\begin{array}{l}\text { Schenckia blumenaviensis K. } \\
\text { Schum. }\end{array}$ & apoju & $\begin{array}{l}\text { Colorante facial (anara- } \\
\text { njado) }\end{array}$ & Raíces & $2404(\mathrm{G})$ \\
\hline \multicolumn{5}{|l|}{ Rutaceae } \\
\hline $\begin{array}{l}\text { Fagara naranjillo (Griseb.) } \\
\text { Engl. }\end{array}$ & $\begin{array}{l}\text { yryvu retyma } \\
(\mathrm{mb}), \text { tem- } \\
\text { betary vuchu } \\
\text { (ch) }\end{array}$ & $\begin{array}{l}\text { Colorante de cestería } \\
\text { (verde oliva) }\end{array}$ & Corteza & $2587(\mathrm{E})$ \\
\hline \multicolumn{5}{|l|}{ Sapindaceae } \\
\hline Cupania vernalis Cambess & yvata'y (ava) & $\begin{array}{l}\text { Espesante de pintura para } \\
\text { cestería. Tintura para tela } \\
\text { (marrón-rojiza) }\end{array}$ & $\begin{array}{l}\text { Cenizas del } \\
\text { leño. Corteza }\end{array}$ & $2529(\mathrm{E})$ \\
\hline Matayba elaeagnoides Radlk. & yvata'y (kuña) & $\begin{array}{l}\text { Espesante de pintura para } \\
\text { cestería. Tintura para tela } \\
\text { (marrón-rojiza) }\end{array}$ & $\begin{array}{l}\text { Cenizas del } \\
\text { leño. Corteza }\end{array}$ & $2512(\mathrm{E})$ \\
\hline \multicolumn{5}{|l|}{ Scrophulariaceae } \\
\hline $\begin{array}{l}\text { Escobedia grandiflora (L. f.) } \\
\text { Kuntze }\end{array}$ & ysypo ju & $\begin{array}{l}\text { Colorante para telas y } \\
\text { para grasa bovina fundida } \\
\text { (amarillo) }\end{array}$ & Raíces & ----- \\
\hline
\end{tabular}

Solanaceae 


\begin{tabular}{|c|c|c|c|c|}
\hline ESPECIE & NOMBRE & USO & PARTE & TESTIGO \\
\hline
\end{tabular}

Verbenaceae

Vitex megapotamica

taruma

Colorante de cestería

Corteza.

$8308(\mathrm{SI})$

(Spreng.) Moldenke

(marrón). Tornar más

Cenizas de la

oscuro a tintura para tela

y cestería.

\section{SPERMATOPHYTA-}

GIMNOSPERMAE

\section{Araucariaceae}

Araucaria angustifolia (Ber- kurí tol.) Kuntze
Barniz para tallas en madera (rojizo)
Resina de los nudos presentes en la inserción de ramas
$5467(\mathrm{G})$ 
BONPLANDIA 19(1). 2010 